УДК $811.161 ’ 42(045)$

\title{
А.А. Биюмена
}

\section{ЭТНИЧЕСКАЯ ТОЛЕРАНТНОСТЬ В ПЕЧАТНОМ МЕДИАДИСКУРСЕ}

В статье рассматривается дискурс этнической толерантности в современных белорусских печатных изданиях. Анализируются основные медиатопики газетных статей, формирующих толерантное отношение к представителям различных стран, наций и этнических групп: мигранты и национальные меньшинства, иностранные студенты и интернациональные браки, а также страны, с которыми сотрудничает Республика Беларусь. Определены ведущие стратегии репрезентации представителей различных этнических групп в печатном медиадискурсе Беларуси (стратегии позитивного и негативного позиционирования, солидаризации и информирования), описаны эксплицирующие их ключевые лексемы. Выявлено, что одной из целей дискурса этнической толерантности в белорусской прессе выступает формирование и поддержание имиджа белорусского государства как страны, благоприятной для проживания не только иностранцев, но и любых категорий граждан. Результаты исследования доказывают детерминированность дискурса толерантности экстралингвистическими факторами - социальными, политическими, экономическими и т. д.

Ключевые слова: медиадискурс, пресса, толерантность, мигранты, медиатопик, коммуникативная стратегия.

DOI: $10.35634 / 2412-9534-2021-31-5-963-970$

В современном мире, характеризующемся тесными контактами между государствами и народами, особую роль играет понятие толерантности. В различных гуманитарных науках оно имеет множество интерпретаций, акцентирующих различные компоненты его содержания.

В наиболее общем виде данный концепт можно трактовать как «взгляд на мир без устойчивых негативных эмоций и оценок» [32, с. 5-6]. Толерантность часто понимают как уважение и добровольное принятие различных ценностей, культур и способов выражения личности, стремление к достижению доброжелательных и гармоничных взаимоотношений в обществе [1, с. 9; 16, с. 183; 17, с. 137]. Семантически она оказывается тесно связанной с понятиями терпимости, миролюбия, взаимного уважения, вежливости, терпения, бесконфликтности, сочувствия [18, с. 59; 20, с. 194], а также является одной из важнейших предпосылок формирования правовой и политической культуры и избавления от негативных стереотипов и предрассудков [12, с. 159].

В монографии «Коммуникативные аспекты толерантности» И.А. Стернин и К.М. Шилихина определяют толерантность как «терпение к другому, иному, не такому, как ты» [32, с. 18]. Ю.В. Клюев рассматривает толерантность как особую качественную характеристику социального взаимодействия в современном информационном обществе и отмечает, что главным проводником и инструментом толерантности в социуме выступают средства массовой коммуникации, а ее инициаторами и организаторами социального диалога должны быть лидеры государства [16 с. 188]. Толерантность также исследуется как коммуникативная и социолингвокультурологическая категория, отражающая национальную специфику языка [19], как часть культурного концепта, составляющая ядерную зону лингвокультурного поля, которое также включает лексемы, на ассоциативном и семантическом уровне связанные с терпением, терпимостью и ненасилием [32].

Дискурс толерантности представляет собой социальное взаимодействие коммуникантов (индивидов, социальных групп, народов, наций и государств) с целью достижения взаимопонимания относительно разделяющих их спорных вопросов, основанное на взаимопомощи, солидарности, равноправии, и призванное воспитывать уважение к Иному [1, с. 12; 4]. В его основе лежит идея об индивидуальной неповторимости коммуникантов и их прав [19, с. 193]. В подавляющем большинстве случаев этот дискурс является институциональным - медийным, политическим, административным и т. д. [23, с. 53; 35].

Традиционно выделяют такиетипы толерантности как политическая, религиозная, экономическая, социокультурная, межличностная и т. д. [16; 33]. Т.В. Романова считает толерантность содержанием определенного социального регулятива, определяющего взгляды, которым необходимо следовать, в то время как речевой формой его проявления является политкорректность как одна из коммуникативных характеристик неконфликтного речевого поведения наряду с вежливостью и тактичностью $[24$, c. 44]. Она пишет, что «именно принцип толерантности является идеологической основой 
политкорректности и политкорректного языка», а политическая корректность - это способ достижения толерантности [24, с. 44].

По мнению других исследователей, политическая корректность представляет собой содержательно более узкий феномен по отношению к толерантности, так как она охватывает лишь определенные группы людей, а именно категории, которые могут подвергаться дискриминации: национальные и сексуальные меньшинства, инвалиды, малоимущие, возрастные, гендерные и некоторые другие группы [33].

Один из типов толерантности, часто находящий отражение в средствах массовой коммуникации - этническая толерантность, обращение к которой весьма актуально в контексте современных миграционных процессов. Этническая толерантность, возникающая на основе признания ценностей этнокультурного разнообразия и раскрытия духовного потенциала каждой нации, предполагает готовность идти на контакт с представителями других этносов, возможность поддерживать дружеские отношения, проявлять взаимовыручку, сотрудничать и приходить к компромиссу с ними [34].

Целью статьи является выявление основных медиатопиков в публикациях о представителях различных национальных и этнических групп в белорусской прессе, а также определение ведущих стратегий их репрезентации и выделение эксплицирующих данные стратегии ключевых лексем на материале статей современных белорусских республиканских, областных и районных газет, размещенных на их Интернет-порталах.

Исследователи отмечают важность тематического репертуара, или определенного набора тем, характеризующего дискурс толерантности, для его эффективного функционирования, поскольку тематический репертуар в значительной степени определяется социокультурным контекстом и общей информацией о деятельности социальной группы [14, с. 24; 19, с. 195; 32, с. 12]. Результаты исследования тематики газетного дискурса этнической толерантности представлены в табл. 1.

Таблица 1

Тематика белорусского газетного дискурса этнической толерантности

\begin{tabular}{|l|l|l|}
\hline № & \multicolumn{1}{|c|}{ Тематический блок } & \multicolumn{1}{|c|}{ Ключевые лексемы } \\
\hline 1. & $\begin{array}{l}\text { Мигранты, } \\
\text { национальные меньшинства }\end{array}$ & $\begin{array}{l}\text { Мигрант, иностранец, беженец, переселенец, община, } \\
\text { переехать }\end{array}$ \\
\hline 2. & Иностранные студенты & Дружить, успешный \\
\hline 3. & Браки с иностранцами & Заключить брак, любовь, иностранец, международный \\
\hline 4. & Международные отношения & $\begin{array}{l}\text { Сотрудничество, партнерство, партнер, дружба, братский, } \\
\text { связь, соглашение, кооперация, совместный, взаимодействие }\end{array}$ \\
\hline
\end{tabular}

Чаще всего статьи, которые составляют белорусский газетный дискурс толерантности, относящийся к представителям различных государств и национальностей, посвящены мигрантам и национальным меньшинствам, иностранным студентам, бракам с иностранцами и международным контактам в области политики, экономики, социальных проектов и т. п.

Публикации о мигрантах в белорусской прессе немногочисленны в связи тем, что данный феномен в стране не носит массового характера. Начиная с 2014 г. в связи с событиями на Украине медиадискурс пополнился материалами о беженцах из этой страны, также в корпусе анализируемых текстов встретились статьи о переселенцах из России, Кубы и Узбекистана: Как сообщила заместитель председателя областной организаџчи БОКК Олеся Костюк, пилотная программа помощчи «Микроэкономические инициативы для украинских переселенцев, находящихся на территории Республики Беларусь в 2017-2018 годах» успешно реализуется с июня прошлого года [3].

Основная цель данных статей - демонстрация того, как успешно переселенцы адаптировались к жизни на новом месте, поэтому речь в них часто идет о помощи со стороны органов власти и о том, что мигрантам нравится жизнь в новых условиях: Нас сразу же определили в общежитие, выделили обеды в столовой, через два дня дали отдельное жилье. Оперативно решился вопрос с пропиской, девочки мои получили белорусское гражданство, муж - вид на жительство ... Как инженерэнергетик Вера Андреевна занимается оперативно-ремонтными работами, тем же энергосбережением и т. д. Имея больиой практический опыт, трудностей в работе не ошущяает: «Здесь удобно работать, особых проблем нет» [9]. 
Поскольку проблема межнациональных конфликтов в Республике Беларусь также не входит в число острых социальных вопросов, в прессе публикуется не так много статей, посвященных национальным меньшинствам. В большинстве случаев они представляют собой информирующие материалы, рассказывающие о культурном укладе, традициях и обычаях той или иной этнической группы: Клеик в наши дни продолжает оставаться одним из религиозных иентров белорусских татар. $B$ городе действует молитвенный дом мусульман, где два раза в месяи собираются на намаз представители местной общины. Сейчас она объединяет почти пять десятков клетчан [10].

В последние годы в Республику Беларусь приезжает все больше иностранных студентов из самых разных стран, что находит отражение на страницах белорусских печатных изданий. Публикации о таких студентах обычно фокусируются на двух темах. Во-первых, в них часто описываются отличия иностранной молодежи от белорусов, а также те стороны жизни в Беларуси, которые вызывают у зарубежных студентов удивление (например, одна из статей называется «Темнокожие студенты любят белорусскую зиму [8]). Вторая группа статей о зарубежных студентах рассказывает истории успеха - они хорошо учатся, успешно осваивают русский и белорусский языки, знакомятся с местной культурой, занимаются спортом и активно участвуют в общественной жизни: - $3 a$ три года я неплохо выучила русский язык. И тут мне помог футбол, ведь я играю вместе с белорусскими девочками за женскую команду университета. Теперь могу самостоятельно сходить в какое-нибудь место. Например, не так давно была на постановке «Лебединое озеро» в Большом театре. А еще мы летом вместе с друзьями из Казахстана ездили в Гродно. Мне он чем-то напомнил итальянский город из одного фильма: красивые здания, пешеходные улочки, живописная набережная, приветливые люди, - рассказывает Ева [31].

Статьи о браках с иностранцами также нередко встречаются на страницах белорусских печатных изданий. Они представляют собой либо информационные материалы статистического характера от соответствующих государственных служб, либо истории конкретных семей, в которых один из супругов - гражданин иностранного государства: За семь месячев зарегистрировано в г. Речище $и$ районе 419 браков, из них - 298 в торжественной обстановке. 41 брак заключен с иностранцами: гражданами Российской Федерации, Украины, Грузии, Молдовы, Эстонии, Туриии, Азербайджана, Германии, Израиля [11]; Украинка Татьяна Осипчук из города Днепра и белорус Павел Ивуть из Щучина встретились во всемирной паутине, чтобы строить красивую реальную жизнь [21].

Еще один важный медиатопик этнического толерантного дискурса белорусской прессы - международные контакты и сотрудничество с представителями различных государств. В них подчеркиваются партнерские и дружеские отношения Республики Беларусь со многими странами, а также описываются международные соглашения и проекты, а в качестве ключевых слов используются лексемы с семантикой сотрудничества: В Гомеле презентовали проект международной технической помощи инвалидам Беларуси и Украины. Укрепление международных контактов между организачиями инвалидов Украины и Беларуси для совместных решений по интеграчии людей с инвалидностью в спорт и туризм - его основная иель, продекларированная на встрече в областной научнотехнической библиотеке [4]; В эти дни Александр Лукашенко провел двусторонние встречи с премьер-министром Пакистана Навазом Шарифом и Президентом Туриии Реджепом Тайипом Эрдоганом. Стороны обсудили реализацию достигнутых ранее договоренностей, а также перспективы развития сотрудничества между странами в различных сферах. В частности, была отмечена необходимость активизировать работу по созданию совместных производств в Пакистане и Туриии. Также лидеры стран обстоятельно рассмотрели развитие ситуации в регионе в сфере безопасности, межправительственное и межпарламентское сотрудничество [5].

Стратегии репрезентации представителей различных этнических групп в печатном медиадискурсе Беларуси представлены в табл. 2.

В качестве первой аксиомы, характеризующей условия возникновения дискурса толерантности, Е.А. Кротков и Е.А. Кожемякин называют признак инаковости, предполагающий наличие у людей или социальных групп, вступающих в отношения, социально значимых различий, которые могут стать источником конфликтов и противоречий [17, с. 137]. Поэтому популярной стратегией в дискурсе толерантности белорусских СМИ является стратегия позитивного позиционирования, цель которой заключается в том, чтобы представить объект с положительной стороны. Дискурс толерантности характеризуется ярко выраженным аксиологическим модусом [25] - в нем представители разнообразных государств и национальных групп практически всегда характеризуются положительно. 
Основные стратегии в белорусском газетном дискурсе этнической толерантности

\begin{tabular}{|c|l|l|}
\hline № & \multicolumn{1}{|c|}{ Стратегия } & \multicolumn{1}{c|}{ Ключевые лексемы } \\
\hline 1. & $\begin{array}{l}\text { Позитивного } \\
\text { позиционирования }\end{array}$ & $\begin{array}{l}\text { Радость, восторг, приятно удивлен, нравится, охотно, забавно, красиво, } \\
\text { легко, удобно, полюбить, благодарность, великолепный, грандиозный } \\
\text { Дружелюбность, чистота, спокойствие, стабильность, достаток, скром- } \\
\text { ность, честность, аккуратность, гостеприимность, мир, трудолюбивый }\end{array}$ \\
\hline 2. & Солидаризации & Общий, свой, наш, помощь, поддержка, защита, содействие, дружба \\
\hline 3. & Информирования & Кухня, традиции, обряды и т.д. \\
\hline 4. & $\begin{array}{l}\text { Негативного } \\
\text { позиционирования }\end{array}$ & $\begin{array}{l}\text { Война, конфликт, бомбежка, противостояние, столкновение, обострение, } \\
\text { острый, кровавый, нестабильный, плохо }\end{array}$ \\
\hline
\end{tabular}

Как показывает проведенный анализ, одним из ведущих языковых средств экспликации данной стратегии выступает лексика, выражающая положительные эмоции (любить, нравиться, приятно удивлен, радость, восторг и т.п.): А вот житель Маврикия Калисетти Аппаду Веемен вместе с соотечественниками в нашей стране уже четвертый год и признается: на снегу порезвился вдоволь. Сейчас, правда, восторга и радости стало меньше, да и после учебы не очень хочется снежками бросаться: - Вот если экзамень успешно сдадим, тогда можно будет расслабиться - поиграем. А первый год очень радовались снегу, бросались снежками, снеговиков лепили [8]; Сын хозяев, тринадиатилетний Николай с радостью показывает новые апартаменты [6].

Стратегия позитивного позиционирования реализуется также в публикациях, раскрывающих черты характера и образцы поведения представителей этнических групп, которые могут быть оценены положительно: Белорусский порядок постепенно освоили и иностраниы: в очереди за едой не толкаются, мусор стараются убирать [28].

Интересно, что в статьях об иностранцах (особенно о мигрантах) объектом позитивного позиционирования чаще всего выступает Республика Беларусь, т. е. одной из целей дискурса толерантности выступает формирование и поддержание имиджа белорусского государства как страны, благоприятной для проживания. Когда зарубежные граждане объясняют, почему они приехали в Беларусь, то подчеркивают позитивные черты характера белорусских людей (дружелюбие, скромность, честность, аккуратность, гостеприимство, трудолюбие), а также те стороны жизни в стране, которые их привлекают (чистота, спокойствие, стабильность, достаток, мир): Основное, что привлекло ташкентиев, это дружелюбные гостеприимные гродненцы [6]; Беларусь - спокойная стабильная страна, а Щучин - отличное место для воспитания ребенка: чистый воздух, много зелени, отличная инфраструктура, позитивные люди [21]; Люди, когда-то потерявиие нажситое, мирную жизнь, признаются: наша страна стала для них второй родиной, ведь здесь они обрели спокойствие и стабильность, поддержку и достаток - то, что нами воспринимается как должное [30].

Стратегия негативного позиционирования, противоположная описанной выше стратегии, обычно используется белорусскими журналистами для описания политической, социальной, экономической ситуации в тех государствах, откуда иностранцы приехали в Беларусь (ключевыми словами при ее реализации выступают лексические единицы война, конфликт, кровавый, столкновения и т.д.): Говорят, до последнего надеялись на лучшее, но когда перерывы между бомбежкками сократились донельзя, бросили все [26]; Хотя в некоторых государствах постсоветского пространства конфликты на религиозной и национальной почвах были и остаются довольно острыми. Взять хотя бы противостояние между народами бывших братских республик СССР Армении и Азербайджана, населявшими Карабах, который пережил три волны кровавых межэтнических столкновений и две полномасштабные войны. А в конце сентября там произошло очередное обострение ситуации [30].

Такие материалы призваны вызвать сочувствие аудитории к людям, о которых идет речь в публикациях. Кроме того, сочетание в одних и тех же статьях двух описанных стратегий акцентирует положительные стороны жизни в Республике Беларусь.

Стратегия солидаризации направлена на включение обсуждаемых субъектов в круг «своих», ведь «толерантность руководствуется противопоставлением “свой - чужой”, а не категориями терпимости “хорошо - плохо”» [25, с. 11]. Необходимым условием функционирования дискурса толерантности называют поиск субъектами «общего знаменателя», то есть общего ценностного пространства, позволяющего им вступить в диалог [17, с. 138]. 
Поэтому журналисты стараются найти точки соприкосновения между определенной этнической группой и гражданами Беларуси: Но Пинск тоже связан с еврейской историей», - отметил паломник из Израиля Нахман Клебеи. Пинск называют «полесским Иерусалимом». Первые евреи поселились здесь в XVI веке. Община быстро росла, и до Второй мировой войны большая часть горожсан были евреями. До сих пор в Пинске работает единственная в стране еврейская школа [22]; Одеяние клеикого мулль во время совершения намаза - бело-красный тюрбан и белый халат, вышитый белорусским орнаментом. В рисунке использованы цветы василька [10]. В последнем примере автор статьи привлекает внимание читательской аудитории к белорусским национальным узорам и изображению цветка, являющегося символом Беларуси, на одеянии представителя татарской мусульманской общины.

Средствами реализации стратегии солидаризации часто выступают слова общий, свой, наш: Иностранные студенты в белорусских вузах - это наши будущие «послы» за рубежом, это «наши люди» [29].

Поскольку одним из самых эффективных методов формирования межэтнической толерантности считают организацию контакта и совместной деятельности представителей отличающихся групп $[15$, с. 49$]$, данную стратегию также эксплицируют материалы, в которых речь идет о дружбе, сотрудничестве, взаимодействии, помощи, поддержке: Наша иель - объединить усилия и максимально помочь им самым необходимым [26]; Минск и Душанбе - друзья и стратегические партнеры ... Не иначе как братскими называли и отношения между нашими странами и народами [27].

Стратегия информирования направлена на то, чтобы познакомить читателей с обычаями, традициями различных этнических групп и национальностей, что, в свою очередь, будет способствовать разрушению предрассудков и преодолению ксенофобии: Таджик обязательно пригласит гостя за стол. Будет печально удивляться, если попытаетесь из вежливости отказаться. Там, наоборот, такое поведение считается невежливым. Вам предложат не менее семи смен блюд. Причем последним обязательно будет классический местный плов, и до этого момента выходить из-за стола моветон. Хозяин не то чтобы обидится, но расстроится очень. Будет думать, что сам что-то сделал не так, и корить прежде всего себя за это. Такие вот тонкие струны ментальности этих душевных людей [26]; Корейские блюда достаточно острые, с большим количеством красного периа и пряностей, характерный вкус и запах которым придает кориандр. Гости смогут отведать «Кимпад» из форели с ветчиной, огуриом и рисом [7].

Предпосылкой этнической толерантности является знание, способствующее пониманию других этнокультурных групп и налаживанию с ними контакта: «толерантность предполагает заинтересованное отношение к Другому, желание почувствовать его мироощущение, которое побуждает к работе разум уже потому, что оно - иное, чем-то не похожее на собственное восприятие действительности» $[2$, с. $33-34]$.

Таким образом, белорусский печатный медиадискурс нацелен на формирование этнической толерантности в первую очередь по отношению к мигрантам и национальным меньшинствам, иностранным студентам и международным семьям, а также к странам, с которыми сотрудничает Республика Беларусь. Ведущими стратегиями репрезентации объектов дискурса этнической толерантности в прессе выступают стратегии позитивного и негативного позиционирования, солидаризации и информирования. Как видно из тематики публикаций, толерантность не является самодостаточным феноменом, она детерминирована внешними факторами (межгосударственными контактами и соглашениями, политической и экономической обстановкой в различных государствах и т. д.).

Этническая толерантность предполагает формирование ценностного отношения к представителям других национальностей на основе знания их культурных особенностей, взаимопонимания, взаимоуважения и совместной деятельности. В современном мире медиадискурс этнической толерантности играет значимую роль в гармонизации отношений в обществе, поскольку он предлагает сменить парадигму борьбы и соперничества на парадигму диалога и сотрудничества.

\section{СПИСОК ИСТОЧНИКОВ И ЛИТЕРАТУРЫ}

1. Азараков Л.В. Толерантный дискурс как дискурс ценностно-ориентированного типа // Коммуникативные исследования. 2018. № 4 (18). С. 7-21.

2. Валитова Р.Р. Толерантность: порок или добродетель? // Вестник Московского ун-та. Серия 7. Философия. 1996. № 1. С. 32-40. 
3. Гомельская праўда. 2018. 14 февр.

4. Гомельская праўда. 2018.9 сент.

5. Горецкий вестник. 2017. 17 мая.

6. Гродзенская праўда. 2009. 7 февр.

7. Гродзенская праўда. 2010. 2 июня.

8. Гродзенская праўда. 2010. 6 янв.

9. Гродзенская праўда». 2010. 28 апр.

10. Да новых перамог.2020. 22 окт.

11. Дняпровец. 2016. 24 авг.

12. Добрикова К.А. Культурологическая реализация моделей толерантности (на материале английского языка) // Вестник Челябинского гос. ун-та. 2014. № 7 (336). С. 158-161.

13. Жданова И.И. Толерантный газетный дискурс (на материале русскоязычной зарубежной прессы): дис. ... канд. филол. наук. Мурманск: Мурманск. гос. гуманит. ун-т, 2015. 258 с.

14. Карасик В.И. Языковой круг: личность, концепты, дискурс. М.: ГНОЗИС, 2004. 390 с.

15. Клименко Е.В. Этнические различия и толерантность: к проблеме разработки социально-культурных программ формирования межэтнической толерантности // Вестник Санкт-Петербургского гос. ун-та культуры и искусств. 2012. № 3 (12). С. 46-50.

16. Клюев Ю.В. Политический массмедиадискурс в демократическом развитии социума. СПб.: Изд-во СПбГЭТУ «ЛЭТИ», 2018. 246 с.

17. Кротков Е.А. Кожемякин Е.А. Дискурс толерантности // Дискурс-Пи. 2013. № 3 (13). С.137-138.

18. Мельничук А.И. Толерантность и интолерантность в коммуникативном дискурсе СМИ // Феномен родного языка: коммуникативно-лингвистический, социокультурный, философский и психологический аспекты: сб. науч. ст. Витебск: ВГУ им. П.М. Машерова, 2018. С. 58-61.

19. Могилевич, Б.Р. Дискурс коммуникативной толерантности // Вестник Московского ун-та. Серия 18. Социология и политология. 2016. Т. 22, № 3. С. 192-201.

20. Нагаева К.Э. Терпение, терпимость, толерантность в русской языковой картине мира // Вестник Московского гос. лингвистического ун-та. Гуманитарные науки. 2018. № 12 (805). С. 186-196.

21. Народная газета. 2020. 23 окт.

22. Полесская правда. 2020. 15 сент.

23. Растатуева С.Г. Репрезентация концепта «Толерантность» в русском языке: дис. ... канд. филол. наук. Елец: Елец. гос. ун-т им. И.А. Бунина, 2008. 173 с.

24. Романова Т.В. Толерантность и политкорректность: аналитический обзор современного состояния проблемы (лингвистический аспект) // Политическая лингвистика. 2015. № 2 (52). С. 39-49.

25. Романова Т.В., Малафеев А.Ю., Морозова Н.Н., Климова (Фокина) М.А. Толерантность как культурная, политическая, лингвистическая проблема: (анализ материалов СМИ и политического дискурса). Н. Новгород: Деком, 2017. 300 c.

26. СБ Беларусь сегодня. 2014. 14 авг.

27. С СБ Беларусь сегодня. 2019. 29 июня.

28. СБ Беларусь сегодня. 2020. 16 сент.

29. СБ Беларусь сегодня. 2020. 30 янв.

30. Сельская газета. 2020. 8 окт.

31. Сельская газета». 2019. 21 окт.

32. Стернин И.А., Шилихина К М. Коммуникативные аспекты толерантности. Воронеж: ИСТОКИ, 2001.110 с.

33. Фурманова С.Л., Компаниец И.М., Теплякова С.М. Политическая корректность: постановка проблемы // Вестник Российского гуманитарного научного фонда. 2015. № 2 (79). С. 174-186.

34. Юдина О.И. Аксиологический аспект этнической толерантности // Современные проблемы науки и образования. 2014. № 4. С. 52-60.

35. Южакова Ю.В. Толерантность массово-информационного дискурса идеологической направленности: дис. ... канд. филол. наук. Челябинск: Челяб. гос. ун-т, 2007. 203 с.

Биюмена Анна Александровна, кандидат филологических наук, доцент, докторант кафедры речеведения и теории коммуникации Минский государственный лингвистический университет 220034, Республика Беларусь, г. Минск, ул. Захарова, 21 E-mail: a-mesyats@tut.by 


\title{
A.A. Biyumena \\ ETHNIC TOLERANCE IN PRINT MEDIA DISCOURSE
}

\author{
DOI: $10.35634 / 2412-9534-2021-31-5-963-970$
}

The article examines the discourse of ethnic tolerance in modern Belarusian print media. The main media topics of the newspaper articles that form a tolerant attitude towards representatives of various countries, nations and ethnic groups are analyzed. They include migrants and national minorities, foreign students and international marriages, as well as countries the Republic of Belarus cooperates with. The leading strategies of representing various ethnic groups in the print media discourse are determined (strategies of positive and negative positioning, solidarity and information). The key lexemes explicating these strategies are described. The study reveals that one of the goals of the ethnic tolerance discourse in the Belarusian press is to form and maintain the image of the Belarusian state as a country favorable for living. The results of the study prove that tolerance discourse is determined by extralinguistic factors - social, political, economic, etc.

Keywords: media discourse, press, tolerance, migrants, media topic, communication strategy.

\section{REFERENCES}

1. Azarakov L.V. Tolerantnyj diskurs kak diskurs cennostno-orientirovannogo tipa [Azarakov,L.V. Tolerant discourse as a value-oriented discourse] // Kommunikativnye issledovaniya. 2018. № 4 (18). S. 7-21. (In Russian)

2. Valitova R.R. Tolerantnost': porok ili dobrodetel'? [Valitova, R.R. Tolerance: vice or virtue?] // Vestnik Moskovskogo un-ta. Ser. 7. Filosofiya. 1996. №1. S.32-40. (In Russian)

3. Gomel'skaya prauda. 2018. 14 Febr.

4. Gomel'skaya prauda. 2018. 9 Sept.

5. Goreckij vestnik. 2017. 17 May.

6. Grodzenskaya prauda. 2009. 7 Febr.

7. Grodzenskaya prauda. 2010. 2 Jan.

8. Grodzenskaya prauda. 2010. 6 Jan.

9. Grodzenskaya prauda. 2010.28 Apr.

10. Da novyh peramog.2020. 22 Oct.

11. Dnyaprovec. 2016. 24 Aug.

12. Dobrikova K.A. Kul'turologicheskaya realizaciya modelej tolerantnosti (na materiale anglijskogo yazyka) [Dobrikova K.A. Cultural implementation of tolerance models (based on the English language)] // Vestnik Chelyabinskogo gos. un- ta. 2014. № 7 (336). S. 158-161. (In Russian)

13. Zhdanova I.I. Tolerantnyj gazetnyj diskurs (na materiale russkoyazychnoj zarubezhnoj pressy) [Zhdanova, I.I. Tolerant newspaper discourse (based on the material of the Russian-language foreign press)]: Dis. ... kand. filol. nauk. Murmansk: Murmansk. gos. gumanit. un-t, 2015. 258 s. (In Russian)

14. Karasik V.I. Yazykovoj krug: lichnost', koncepty, diskurs [Karasik, V.I. Language circle: personality, concepts, discourse]. Moscow: GNOZIS, 2004. 390 s. (In Russian)

15. Klimenko E.V. Etnicheskie razlichiya i tolerantnost': k probleme razrabotki social'no-kul'turnyh programm formirovaniya mezhetnicheskoj tolerantnosti [Klimenko, E.V. Ethnic differences and tolerance: on the problem of developing socio-cultural programs for the formation of interethnic tolerance] // Vestnik Sankt-Peterburgskogo gos. un-ta kul'tury i iskusstv. 2012. № 3 (12). S. 46-50. (In Russian)

16. Klyuev Yu.V. Politicheskij massmediadiskurs v demokraticheskom razvitii sociuma [Klyuev, Yu.V. Political mass media discourse in the democratic development of society]. St-Petersburg: Izd-vo SPbGETU «LETI», 2018. $246 \mathrm{~s}$. (In Russian)

17. Krotkov E.A. Kozhemyakin E.A. Diskurs tolerantnosti [Krotkov, E.A. Tolerance discourse] // Diskurs-Pi. 2013. № 3 (13). S. 137-138. (In Russian)

18. Mel'nichuk A.I. Tolerantnost' i intolerantnost' v kommunikativnom diskurse SMI [Mel'nichuk, A.I. Tolerance and intolerance in the communicative media discourse] // Fenomen rodnogo yazyka: kommunikativno-lingvisticheskij, sociokul'turnyj, filosofskij i psihologicheskij aspekty: sb. nauch. st. Vitebsk: VGU im. P.M. Masherova, 2018. S. 58-61. (In Russian)

19. Mogilevich B.R. Diskurs kommunikativnoj tolerantnosti [Mogilevich, B.R. Discourse of communicative tolerance] // Vestnik Moskovskogo un-ta. Ser. 18. Sociologiya i politologiya. 2016. T. 22. № 3. S. 192-201. (In Russian)

20. Nagaeva K.E. Terpenie, terpimost', tolerantnost' $v$ russkoj yazykovoj kartine mira [Nagaeva, K.E. Patience, terpimost', tolerance in the Russian language picture of the world] // Vestnik Moskovskogo gos. lingvisticheskogo un-ta. Gumanitarnye nauki. 2018. № 12 (805). S. 186-196. (In Russian)

21. Narodnaya gazeta. 2020. 23 Oct.

22. Polesskaya pravda. 2020. 15 Sept. 
23. Rastatueva S.G. Reprezentaciya koncepta «Tolerantnost'»v russkom yazyke [Rastatueva S.G. Representation of the concept "Tolerance" in the Russian language]: Dis. ... kand. filol. nauk. Elec: Elec. gos. un-t im. I.A. Bunina, 2008. 173 s. (In Russian)

24. Romanova T.V. Tolerantnost' i politkorrektnost': analiticheskij obzor sovremennogo sostoyaniya problemy (lingvisticheskij aspekt) [Romanova, T.V. Tolerance and political correctness: an analytical review of the current state of the problem (linguistic aspect)] // Politicheskaya lingvistika. 2015. № 2 (52). S. 39-49. (In Russian)

25. Romanova T.V., Malafeev A.Yu., Morozova N.N., Klimova (Fokina) M.A. Tolerantnost' kak kul'turnaya, politicheskaya, lingvisticheskaya problema: (analiz materialov SMI i politicheskogo diskursa) [Romanova T.V., Malafeev, A.Yu., Morozova N.N., Klimova (Fokina) M.A. Tolerance as a cultural, political, linguistic problem: (analysis of media materials and political discourse)]. N. Novgorod: Dekom, 2017. 300 s. (In Russian)

26. SB Belarus' segodnya. 2014. 14 Aug.

27. SB Belarus' segodnya. 2019. 29 June.

28. SB Belarus' segodnya. 2020. 16 Sept.

29. SB Belarus' segodnya. 2020. 30 Jan.

30. Sel'skaya gazeta. 2020. 8 Oct.

31. Sel'skaya gazeta». 2019. 21 Oct.

32. Sternin I.A., Shilihina K.M. Kommunikativnye aspekty tolerantnosti [Sternin, I.A., Shilihina, K.M. Communicative aspects of tolerance]. Voronezh: ISTOKI, 2001. 110 s. (In Russian)

33. Furmanova S.L., Kompaniec I.M., Teplyakova S.M. Politicheskaya korrektnost': postanovka problemy [Furmanova S.L., Kompaniec I.M., Teplyakova S.M. Political correctness: problem statement] // Vestnik Rossijskogo gumanitarnogo nauchnogo fonda. 2015. № 2 (79). S. 174-186. (In Russian)

34. Yudina O.I. Aksiologicheskij aspekt etnicheskoj tolerantnosti [Yudina O.I. Axiological aspect of ethnic tolerance] // Sovremennye problemy nauki i obrazovaniya. 2014. № 4. S. 52-60. (In Russian)

35. Yuzhakova Yu.V. Tolerantnost' massovo-informacionnogo diskursa ideologicheskoj napravlennosti [Yuzhakova Yu.V. Tolerance of mass-informational discourse of ideological orientation]: Dis. ... kand. filol. nauk. Chelyabinsk: Chelyab. gos. un-t, 2007. 203 s. (In Russian)

Biyumena A.A., Candidate of Philology, Associate Professor,

Doctoral student at Speech Studies and Theory of Communication Department

Minsk State Linguistic University

Zakharova st., 21, Minsk, Belarus, 220034

E-mail: a-mesyats@tut.by 